DOI: 10.1002/adhm.201700836

\title{
Article type: Progress Report \\ Dynamic and Responsive Growth Factor Delivery from Electrospun and Hydrogel Tissue Engineering Materials
}

Dr. KiaraF.Bruggeman ${ }^{1}$, Dr. Richard J. Williams ${ }^{2,3}$, Prof. David R. Nisbet ${ }^{1,3} *$
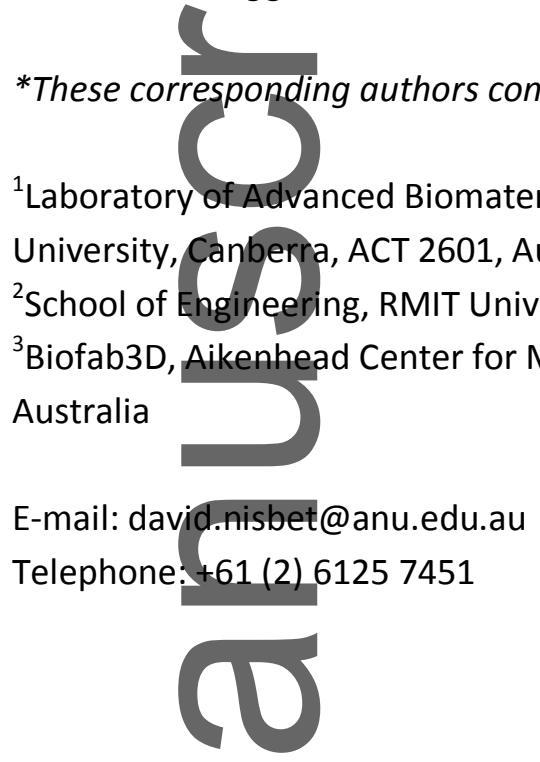

Keywords

tissue engineering; drug delivery; regenerative medicine; hydrogel; electrospinning

\begin{abstract}
Tissue engineering scaffolds are designed to mimic physical, chemical, and biological features of the extracellular matrix (ECM), thereby providing a constant support that is crucial to improved regenerative medicine outcomes. Beyond mechanical and structural support, the next generation of these materials must also consider the more dynamic presentation and delivery of drugs or growth factors to guide new and regenerating tissue development. These two aspects have been explored expansively separately, but they must interact synergistically to achieve optimal regeneration. This review explores common tissue engineering materials types, electrospun polymers and hydrogels, and strategies used for incorporating drug delivery systems into these scaffolds.
\end{abstract}

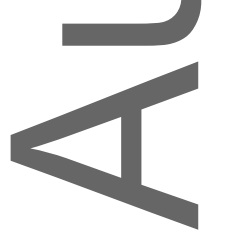

This is the author manuscript accepted for publication and has undergone full peer review but has not been through the copyediting, typesetting, pagination and proofreading process, which may lead to differences between this version and the Version of Record. Please cite this article as doi:

10.1002/adhm.201700836.

This article is protected by copyright. All rights reserved. 


\section{Introduction}

The goal of tissue engineering for regenerative medicine is to stimulate the growth of new, healthy tissue. Strategies to achieve this include encouraging the activation of host cells for the repair of damaged tissue or tissue replacement with new cells via cell replacement therapy (CRT). ${ }^{[1]}$ In either case, specifically designed tissue engineering materials or scaffolds are used to mimic the natural extracellular matrix (ECM) and provide an intermediate supportive environment. The material degrades away as it is replaced by new, healthy ECM from regenerating tissue.

The ECM is an incredibly complex fluid environment that connects individual cells within a tissue, both structurally and functionally. Nanofibrous structural proteins are a major component of the $\mathrm{ECM},{ }^{[2]}$ and cell behaviours are heavily influenced by cues from the surrounding microenvironment, provided by the tissue-specific ECM. ${ }^{[3]}$ These cues vary widely, including physical, chemical, and biological properties. For cells to behave as they would in healthy ECM, the synthetic scaffolds must be as mimetic as possible of the desired tissue's ECM. ${ }^{[4]}$

Much research has been done investigating and optimising one material property at a time to mimic the ECM. For example, extensive work has been done tuning material stiffness ${ }^{[5]}$ and the nano/microscale morphology, ${ }^{[6]}$ and these properties have both been shown to significantly affect cell differentiation and proliferation. ${ }^{[7]}$ While tuning an individual biochemical or physical cue can enable study of its effect in isolation and enhance material performance ${ }^{[8]}$ multiple biomimetic cues often have a synergistic effect, such that the overall benefit is greater than the combined individual benefits. ${ }^{[76,9]}$ This makes it important to include and optimise as many aspects of the ECM as synthetically possible in order to achieve the greatest therapeutic benefit.

While tissue engineering materials are designed with degradation in mind, this is often over a relatively long timescale (months to years), and, ideally, the degradation occurs as the material is replaced by healthy tissue and the structural needs change. In the context of drug delivery, which provides trophic rather than structural support, and which occurs on the timescale of hours and weeks, the structural aspects of these materials can be considered comparatively static components. From a design perspective, it is also beneficial to consider them as static while designing drug delivery systemsin the sense that the inclusion of a drug delivery system should not affect the material's ability to provide structural support. Ideal tissue engineering materials should be able to provide independently controlled structural support and drug delivery (Figure 1). Often drug delivery systems are incorporated into existing structurally supportive tissue engineering materials, this review will discuss many of these systems and the ways in which the drug delivery affects the structural and mechanical properties of the materials.

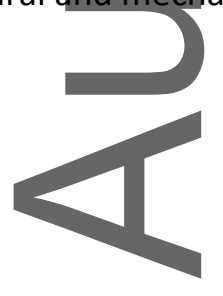

This article is protected by copyright. All rights reserved. 


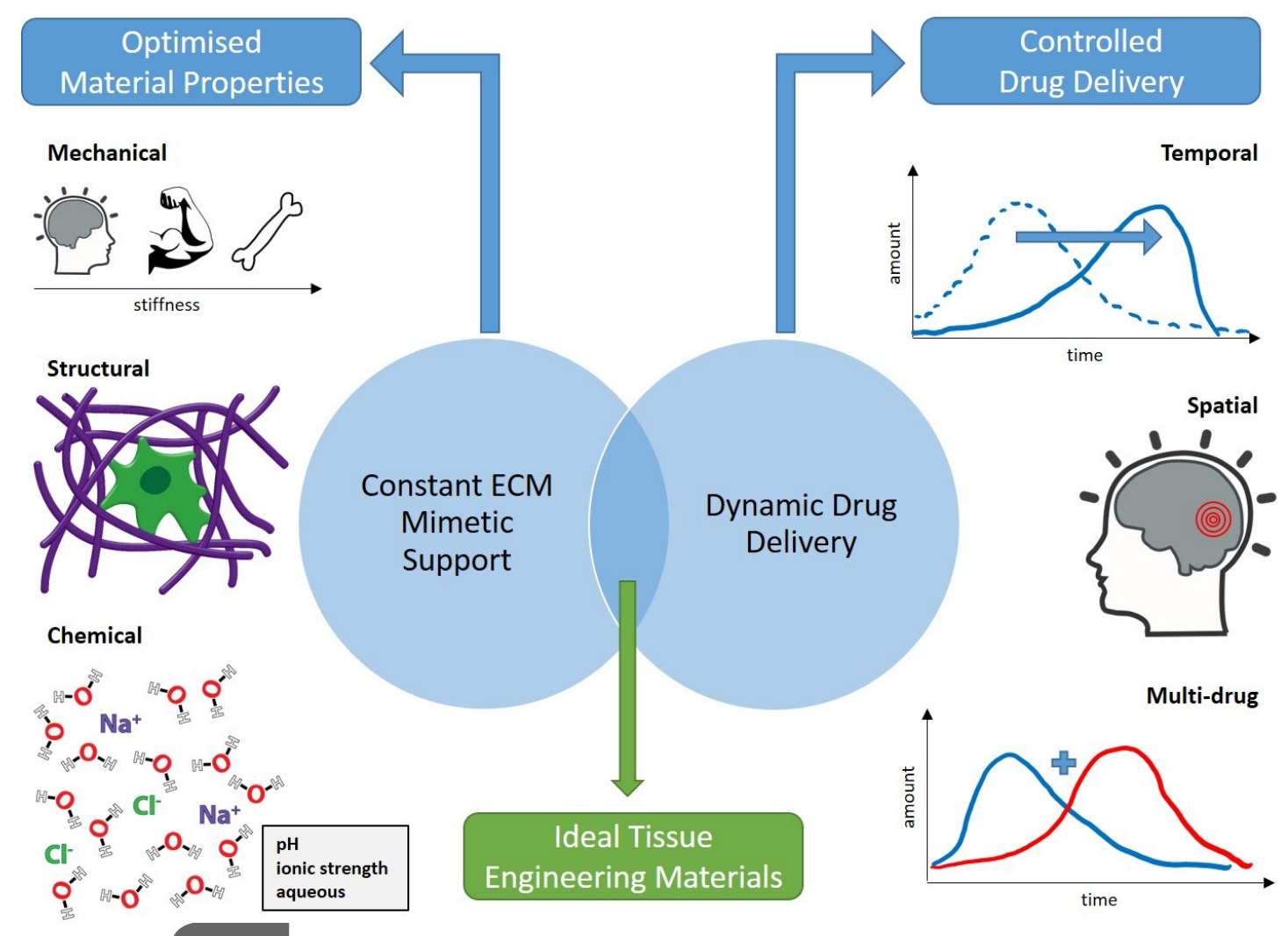

Figure 1: Ideal tissue engineering materials require both optimised material properties and controlled drug delivery. Mechanical properties include matching tissue-specific stiffness. Structural support can be provided by nanofibres. The chemical environment of bodily tissues is aqueous, with specific physiological pH and ionic strength. Temporally controlled delivery requires the ability to delay the release of a drug from a material. Spatially controlled delivery requires localisation of drug within or released from a material. Multi-drug delivery requires distinct release profiles of different drugs from the same material.
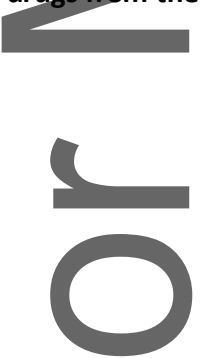

Tissue engineering materials provide a structurally supporting environment that is mimetic of the ECM and supportive of new tissue growth and regeneration. Another important factor in directing cell growth and behaviour is the more dynamic presentation of secreted, soluble growth factors into the ECM! ${ }^{[3]}$ Growth factors are protein signalling molecules that have an important role in determining cell fate and behaviour, and they are inherently short-lived ${ }^{[10]}$ in the order of minutes to hours. ${ }^{[11]}$ Different growth factors are needed at different stages of tissue growth/regeneration, and the order and timing of their delivery is important. ${ }^{[12]}$ For example, for angiogenesis, angiopoietin-1 and platelet derived growth factor BB (PDGF-BB) stabilise newly formed blood vessels after vascular endothelial growth factor (VEGF), fibroblast growth factor (FGF), and angiopoietin-2 provide the disruption of pre-existing vessels and migration to form new immature vessels. ${ }^{[12]}$ Furthermore, in neuroscience applications epidermal growth factor (EGF), which increases proliferation of neural stem/progenitor cells (NSPs), is best delivered initially for 7 days, followed by erythroprotein (EPO) to protect and reduce apoptosis in the new cells. ${ }^{[13]}$ In addition to the order of delivery, different growth factors require different durations. The demyelination process, for example, involves many

This article is protected by copyright. All rights reserved. 
growth factors with different temporal presentation profiles in the cortex, including: initial presentation lasting 2 weeks for glial cell line derived neurotrophic factor (GDNF), initial sustained presentation for FGF-2, and delayed presentation starting after 1 week for transforming growth factor beta-1 (TGF- $\beta 1$ ). ${ }^{[14]}$ While designing constantly supportive ECM mimetic materials focuses on ongoing presentation of biological cues, here a variety of presentation or delivery profiles is required to create the optimal dynamic environment for tissue regeneration.

To provide this dynamic environment growth factors, and other drugs, are being incorporated into tissue engineer materials. When developing drug delivery strategies, there are several important issues that need to be considered. Drugs, including growth factors, function best at doses within a therapeutic window; concentrations above this window can be toxic or produce harmful side effects, while lower concentrations can be ineffective. ${ }^{[10,15]}$ For example, nerve growth factor (NGF) has been shown to support neurite outgrowth in a bell pattern, with the optimal dose at $800 \mathrm{pg} / \mu \mathrm{L}$ in rats, and increasing doses beyond that actually inhibiting neurite outgrowth. ${ }^{[16]}$ This means a design consideration needs to be the control of the timing and rate of the drug delivery, whilst being mindful of its in situ properties. In particular, protein growth factors require sustained presentation, yet are unstable in a physiological environment and degrade within minutes to hours ${ }^{[11,17]}$. In vivo, enzymatic degradation results in very short growth factor half-lives, as low as $3 \mathrm{~min}$ for basic fibroblast growth factor (bFGF) ${ }^{[18]}$ and $45 \mathrm{~min}$ for nerve growth factor (NGF $)^{[19]}$. It is also important to consider the delivery or release profile; most commonly a sustained release is desirable ${ }^{[20]}$ but sometimes a burst release is required for immediate response or a pulsatile release is required to mimic natural processes. ${ }^{[15]}$ While it is common to report on the cumulative delivery, this can hide fluctuations in the ongoing release rate outside of the therapeutic window, and therefore truly controlled delivery profiles must control the ongoing rate of delivery not just the cumulative dose. ${ }^{[21]}$ We have demonstrated the importance of studying ongoing release rate as opposed to cumulative release, and have developed methods to stabilise growth factor delivery, reducing the fluctuations in release rate (Figure 2). ${ }^{[21]}$ While the cumulative profiles appear similar and stable, the actual release rate of the growth factor fluctuates significantly before modification with the polysaccharide chitosan. The delivery site is another major consideration, as drugs can have negative side effects to non-target tissues. ${ }^{[22]}$

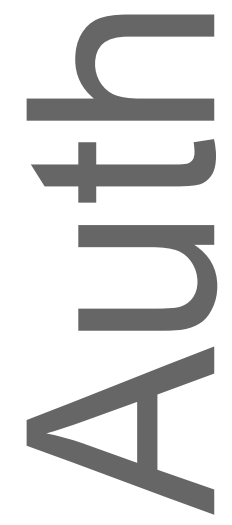

This article is protected by copyright. All rights reserved. 

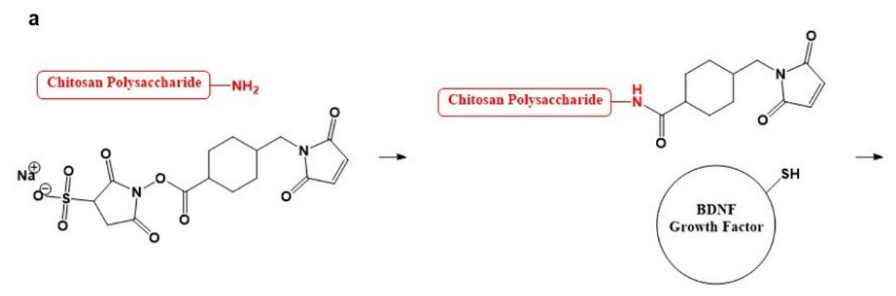

b i
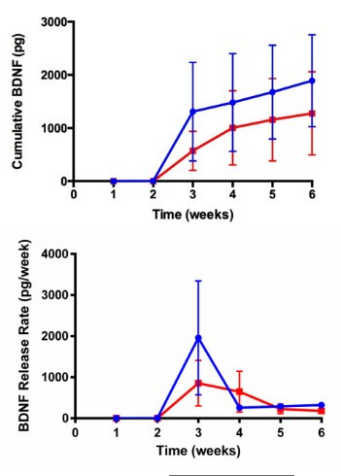
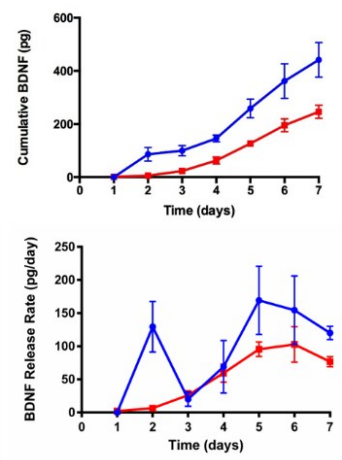

b iii
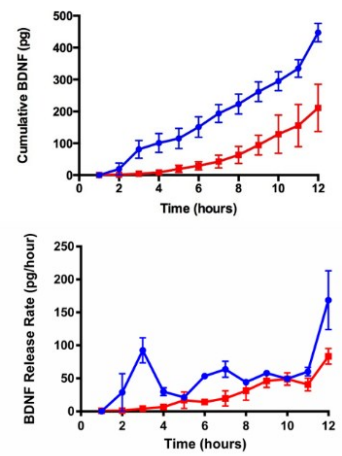
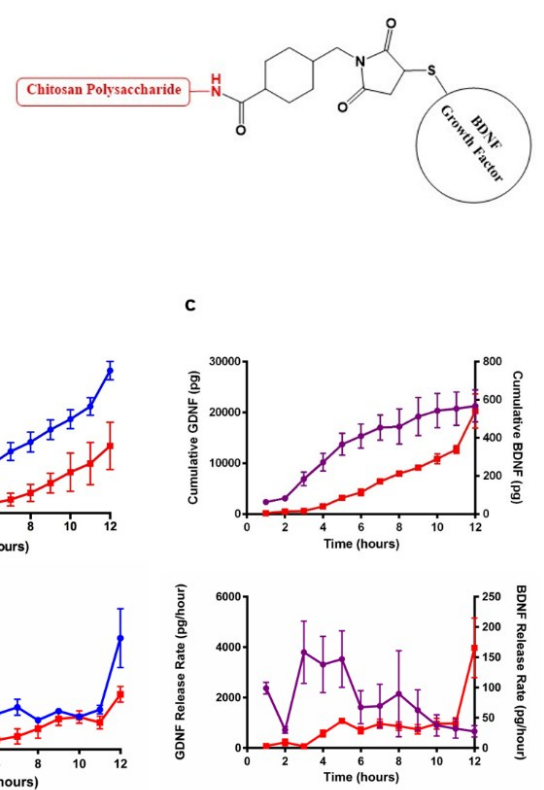

Figure 2: Release rate vs. cumulative release and reducing fluctuations. ${ }^{[21]}$ (a) Chemical scheme of covalent crosslinking between chitosan polysaccharide amine group and BDNF growth factor sulfhydryl group. (b) Weekly (i), daily (ii), and hourly (iii) release profiles of BDNF (blue) and modified BDNF-Chitosan (red) from Fmoc-DDIKVAV self-assembling peptide hydrogels. (c) Hourly, simultaneous release profiles of GDNF (purple) and modified BDNF-Chitosan (red) from the same Fmoc-DDIKVAV hydrogels. Cumulative release profiles (top) show the absolute amount of growth factor released since the beginning of the experiment. Release rate profiles (bottom) show the growth factor reteased in individual samples/time intervals. Data represents mean \pm standard error. Reproduced with permission. ${ }^{[21]}$ Copyright 2016, IOP Publishing.

In an effort to control drug dosage, maximise delivery, and reduce cytotoxicity, the targeted delivery of drugs to the site of therapeutic need is an area of intense research focus. ${ }^{[22]}$ Delivery and targeting methods are becoming increasingly specific. For example, some methods of chemotherapeutic drug delivery involve shielding cytotoxic drugs so they can be introduced systemically into the blood stream, and designing the shielding to undergo localised and selective release only around cancerous cells based on specific indicators such as $\mathrm{pH}$ or overexpression of particular proteins. ${ }^{[23]}$ Localisation of drug delivery can also be achieved simply by incorporating the drug delivery system into a tissue engineering material, as we are discussing here. The tissue engineering material must be implanted at the specific injury or disease site, providing a base for highly localised drug delivery. This is particularly advantageous for regeneration of tissues shielded from the bloodstream, such as the brain, which is protected from systemic drug delivery by a highly selective membrane called the blood brain barrier (BBB). ${ }^{[22]}$ Sustained and controlled delivery to the brain can be achieved using intracerebroventricular (ICV) infusion or micropumps, however, this is very invasive and causes significant tissue damage so much research has focused on using tissue engineering scaffolds as growth factor delivery vehicles as well. ${ }^{[13,24]}$

Tissue engineering materials can be used as a reservoir for sustained and controlled drug delivery as in many instances they are engineered to be minimally invasive (i.e. shear thinning hydrogels) and their inherent biocompatibility means that they can be implanted for long durations. Note that when

This article is protected by copyright. All rights reserved. 
using a reservoir, temporally controlled delivery must be achieved via controlled delay in release from the reservoir. This review discusses methods of incorporating drugs into tissue engineering materials and efforts to control their delivery/presentation. We will discuss a variety of drug delivery systems, with a particular focus on growth factor delivery. We will explore methods in the two most common classes of tissue engineering materials, electrospun materials and hydrogels, including brief contextual explanations of the fabrication and material properties of these materials themselves. Drug delivery systems will be evaluated based on their applicability with growth factors, ability to provide temporally controlled delivery of multiple distinct drugs, and their effect on the properties of the tissue engineering material.

\section{Electrospun Materials}

Electrospinning produces a scaffold in the form of a mesh of nano- to microscale polymer fibres, either randomly oriented or aligned in parallel. ${ }^{[25]}$ The final material is 2-dimensional (2D) at a macro scale but 3-dimensional (3D) at the micro scale and provides a structural mimic of the fibrous structural proteins abundant in the ECM. ${ }^{[26]}$

To produce these materials, a high voltage is applied between a collection plate and spinneret (metal needle) from which a polymer solution is slowly dispensed (Figure 3). This method is simple and versatile; it can be used with any materials that can be dispersed in the spinning solution enough to pass through the spinneret. Previously, we have reviewed the electrospinning process and problems an improvement for the characterisation of the as-spun scaffolds ${ }^{[25,27]}$. We direct the interested reader to these publications, as such discussion is outside the scope of the currently review.

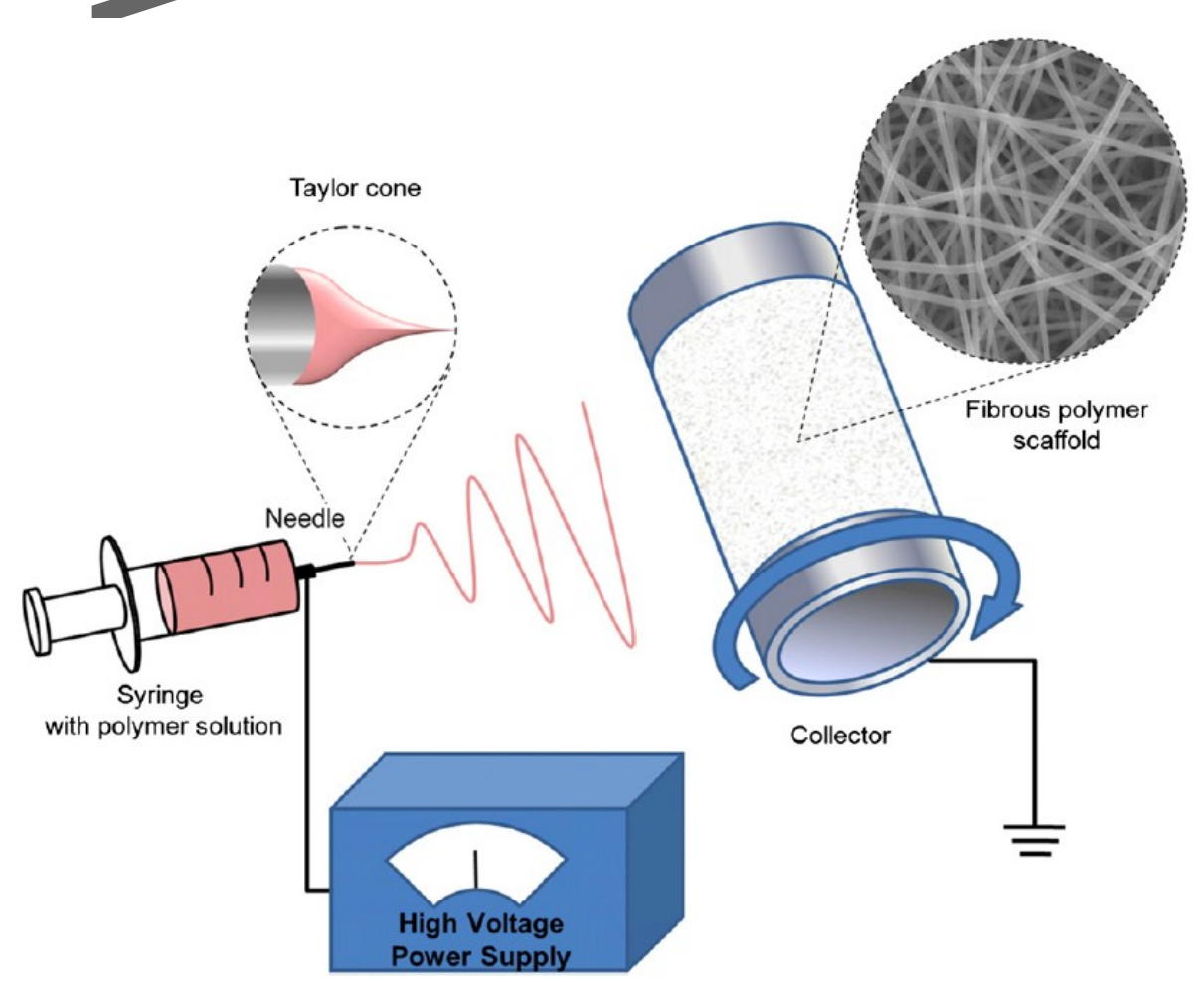

This article is protected by copyright. All rights reserved. 
Figure 3: Scheme of the electrospinning system with major components. ${ }^{[28]} \mathrm{A}$ high voltage is applied between the needle of the spinning solution and the collecting plate, which causes a charge build up at the solution surface and the formation of a Taylor cone. Fibres of the spinning solution are pulled toward the collector to form a fibrous polymer scaffold.

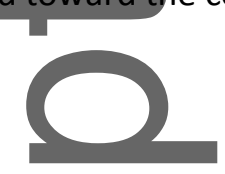

Electrospinning can be used with natural or synthetic scaffold materials and can accommodate many additives, including living cells. ${ }^{[25,29]}$ The tissue response to electrospun nanofibrous scaffolds along with methods of tuning their surface and bulk properties, have been well explored and reviewed. ${ }^{[25-}$ $26,28,30]$ On the micro-scale, the nanofibrous structure can be used to promote specific cell growth, such as neurite extension, via contact guidance. ${ }^{[31]}$ The $2 \mathrm{D}$ nature of these materials makes them ideal for wrapping or bandaging applications where additional support or a barrier is required from the scaffold. One major drawback of these materials is their inability to fill voids, which limits their ability to fully interface with the healthy tissue surrounding an irregularly shaped disease/injury site, and therefore inhibits its full therapeutic potential. ${ }^{[32]}$ While there are some examples of clinical translation ${ }^{[33]}$, overall their translation to a clinical setting have been hindered by issues with consistent production of materials free of residual solvents, ease in sterilization, weak mechanical properties and difficulty in scaling production.

\subsection{Emulsion Electrospinning}

When creating an electrospun scaffold material, the polymer used to form the scaffold is first dissolved to create the spinning solution. As the polymer initially exists in solution, it is possible, via emulsion electrospinning, to add drugs or other active agents directly into this solution to produce a homogeneously loaded scaffold material. ${ }^{[34]}$ With electrospun materials being suited for bandaging applications, drug loaded electrospun mats have been prepared for wound dressings, such as antibacterial tetracycline hydrochloride loaded poly- $\varepsilon$-caprolactone (PCL)/polylactic acid (PLA) blend electrospun materials. ${ }^{[35]}$ These materials showed superior performance to commercial Comfeel wound dressings, with improved water-uptake capacity, $600 \%$ vs. $100 \%$ respectively, as well as adding effective antibacterial properties, showing continuous release of tetracycline hydrochloride over 48 hours and effectively killing all E. coli and S. aureus in agar plates. ${ }^{[35]}$

This approach can be used for protein growth factors, whose large size and instability can be an obstacle for delivery from the blood stream across size-selective membranes such as the BBB. Human $\beta$-nerve growth factor (NGF), in the presence of the stabilising carrier protein bovine serum albumin (BSA), has been successfully electrospun with $\mathrm{PCL}$ dissolved in chloroform $\left(\mathrm{CHCl}_{3}\right)^{[36]}$ and $\mathrm{PCL} /$ poly- $\varepsilon$-caprolactone ethyl ethylene phosphate (PCLEEP) blend in dichloromethane (DCM). ${ }^{\left[{ }^{37]}\right.}$ In both cases the materials demonstrated a sustained, continuous release, measured out to $28^{[36]}$ and 90 days ${ }^{[37]}$ respectively. The bioactivity of NGF was unaffected by the harsh solvents, which was confirmed by neurite outgrowth from neuroblastic PC12 cell line cells in vitro. ${ }^{[37]}$ Both brain derived neurotrophic factor (BDNF) and ciliary neurotrophic factor (CNTF) have been simultaneously loaded into electrospun silk fibroin/poly(ethylene oxide) (PEO) blend, which showed a greater increase in the axonal growth of rat retinal ganglion cells (RGCs) compared to fibres loaded with just one growth factor or fibres alone. ${ }^{[38]}$ 
This method is effective for achieving a single, sustained release profile of growth factors, and while it can be used to deliver multiple growth factors concurrently, it does not offer control over the release or temporal distinction between multiple loaded drugs. To achieve more control of the release properties, more individually customisable methods must be used.

\subsection{Radially Layered Fibres}

Coaxial electrospinning uses concentric spinnerets with distinct spinning solutions in order to produce radially layered fibres. ${ }^{[39]}$ While the potential of this method remains to be extensively explored, with therapeutic proteins yet to be included, we believe it has significant potential to shield a drug loaded core with a degradable or porous outer sheath in order to delay and control the release of drugs. ${ }^{[39]}$ Similar to the wound dressing mats discussed above, biodegradable poly(lactide-co-glycolide) (PLGA) nanofibrous mats have been prepared with tetracycline hydrochloride in the core of each fibre. ${ }^{[39 a]}$ Optimal mats were produced using a smaller amount of drug in the sheath as well, and these mats provided sustained release for 10 days with a reduction in the initial burst release (defined as the percentage of total release achieved in the first hour) from 62 to $44 \%$ compared to blended single-layer fibres. ${ }^{\text {[3a] }}$

The coaxial method can also be used to layer different drugs to provide successive release of multiple agents. ${ }^{[40]}$ Han and Steckl developed a model electrospun material with three distinct radial layers to deliver multiple drugs with distinct release profiles (Figure 4). ${ }^{[40]}$ Using colour dyes as model drugs the dye in the hygroscopic outer sheath layer displayed a burst release, while the dye in the core showed sustained release for 50 hours as it was slowed by an intermediate hydrophobic layer and the other sheath. ${ }^{[40]}$ This method could be employed for any active agent stable in the electrospinning solution, and can also provide a non-solvent layer for active agents unstable in the volatile electrospinning solution.

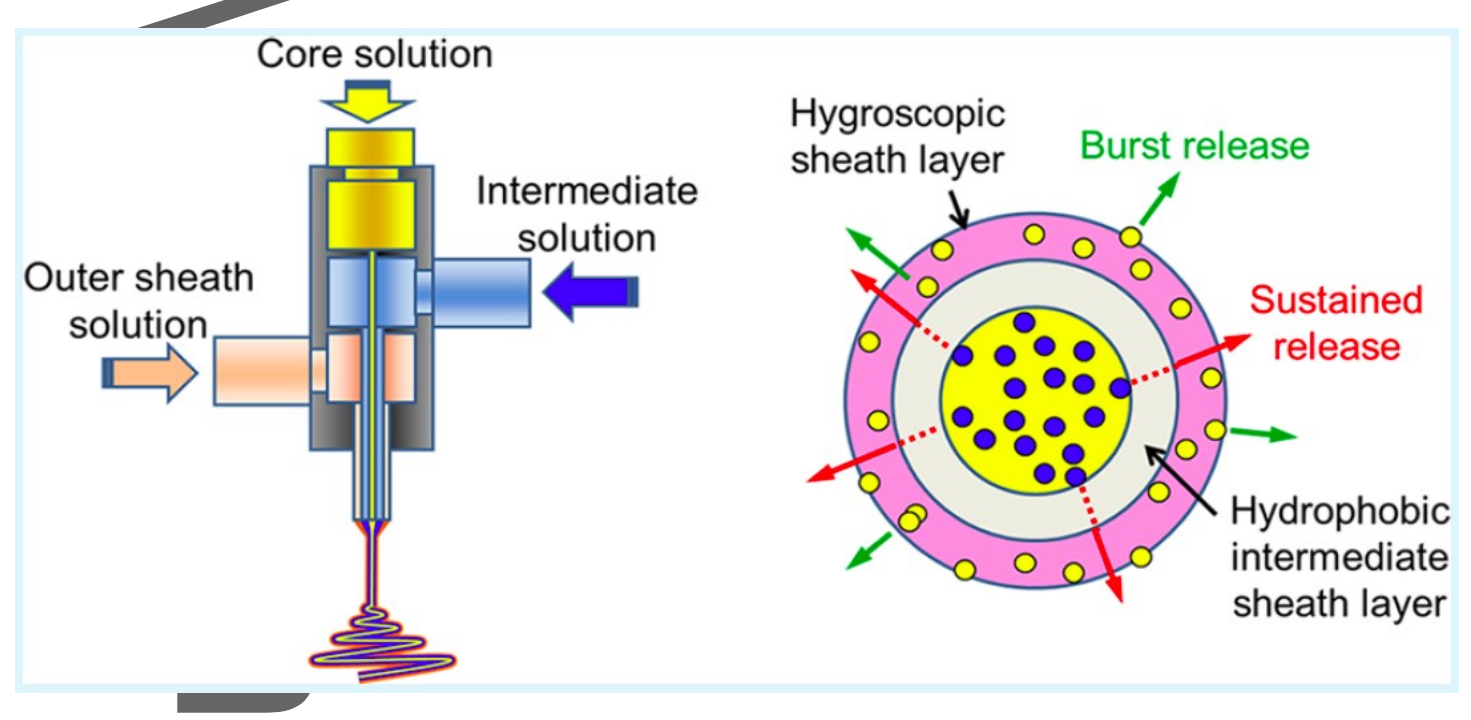

Figure 4: Triaxial Electrospinning of Radially Layered Fibres. ${ }^{[40]}$ Three concentric needles are used to dispense separate spinning solutions to create fibres with three distinct radial layers. Dye added to the other layer displayed a burst release while the dye in the core displayed a sustained release after travelling through the intermediate sheath layer. Reproduced with permission.[40] Copyright 2013, American Chemical Society.

This article is protected by copyright. All rights reserved. 


\subsection{Immobilisation onto Electrospun Materials}

Drugs can be immobilised permanently onto an electrospun scaffold by attaching them using strong covalent bonds (preferably formed through bonding of an otherwise inactive site on the drug molecule). Immobilised drugs can be detected by surrounding cells but not consumed; making this approach applicable to mimic the delivery of secreted, extracellularly active intercellular signalling molecules such as some protein growth factors. Growth factors play an important role in cellular activity, and function as a mechanism for rapid communication between surrounding cells in other parts of the tissue. However, due to this transient signalling role, growth factors naturally degrade rapidly under normal physiological conditions, lasting only minutes to hours when introduced in vivo in soluble form. ${ }^{[1]]}$ For the growth factor to have prolonged effectiveness a sustained delivery system, such as coyalent immobilisation to an electrospun scaffold, is required.

Covalent immobilisation requires the introduction of linkable groups through minimal chemical modification without affecting the desirable function of the molecule. Commercially available crosslinking molecules, such as succinimidyl-4-(N-maleimidomethyl) cyclohexane-1-carboxylate (SMCC) ${ }^{[11,24,41]}$ link two materials by reacting with specific functional groups present on each material. SMCC connects two different molecules between the amine groups of one and the thiol groups of the other, such as by connecting an aminolysed electrospun polymer surface to the thiol group of a free cysteine residue in a protein growth factor. ${ }^{[24]}$ This results in the alteration of one, relatively small chemical moiety on the protein. The immobilised growth factors therefore remain biologically active and their degradation depends on the degradation of the polymer scaffold, allowing them to be presented on the scaffold surface for orders of magnitude longer than soluble growth factors. ${ }^{[1,24,41]}$

Our group has immobilised GDNF onto electrospun PCL scaffolds using SMCC and have shown that GDNF maintained its biofunctionality, inducing improved viability and number of tyrosine hydroxylase immunoreactive $(\mathrm{TH}+)$ cells, for at least 7 days in a neural progenitor cell culture. ${ }^{[11]}$ The growth factor remained detectable by enzyme linked immunosorbent assay (ELISA) after 120 days of storage in $\mathrm{PBS}$ or artificial cerebrospinal fluid. ${ }^{[11]}$ The long term biofunctionality was confirmed by immunoblotting, and the immobilised GDNF growth factor continued to show ongoing ErK phosphorylation after 3 days in the neural stem line SN4741, after the growth factor solution had lost biofunctionality (Figure 5A-D). ${ }^{[1]}$ We have also used this immobilised GDNF in vivo in rat parenchyma to promote engraftment of transplanted neural stem cells. The immobilised GDNF significantly increased the graft cell number, ${ }^{[41]}$ as well as increasing the proportion of Nestin+ neural stem cells and decreasing the proportion of GFAP+ reactive astrocytes (Figure 5A-D). The increase in Nestin is indicative of ongoing support for immature neurons similar to that during the development of the $\mathrm{CNS}^{{ }^{141]}}$ The decrease in reactive astrocytes indicates a reduction in the inflammatory response that leads to glial scarring and limited recovery. ${ }^{[1]}$

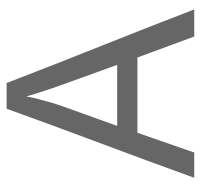

This article is protected by copyright. All rights reserved. 

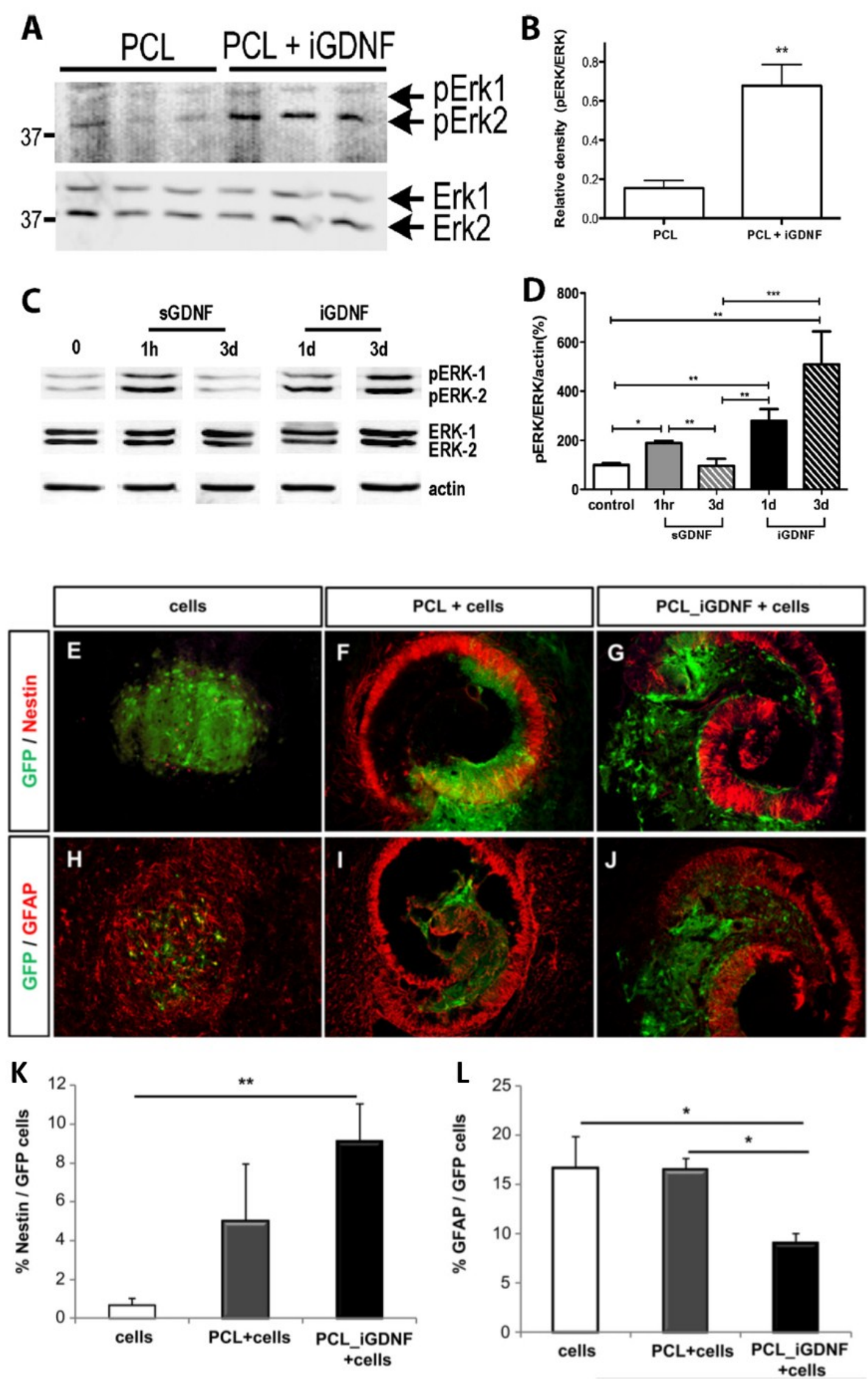

Figure 5: Immobilised growth factor in vitro ${ }^{[11]}$ and in vivo. ${ }^{[41]}$ A-D: Long term biofunctionality of immobilised GDNF confirmed based on phosphorylation of intracellular ErK. Immunoblotting (A, C) and band densities (B, D) of the ErK and 
phosphorylated pErK from SN4741 neural cells. A-B: Comparison of PCL scaffold alone and with immobilised GDNF. C-D: Comparison of GDNF solution and immobilised GDNF over time. Data represent mean \pm SEM, $* p<0.05, * * p<0.01, * * *$ $p<0.001$, student's $t$ test and one-way ANOVA. E-L: Effect of immobilised GDNF on transplanted cells in vivo.

Photomicrographs (E-J) and quantification (K-L) of Nestin+ neural stem cells and GFAP+ astroglia within the GFP+ cell graft. A-D) Reproduced with permission. ${ }^{[11]}$ Copyright 2014, American Society for Biochemistry and Molecular Biology. E-L) Reproduced with permission. ${ }^{[41]}$ Copyright 2012, Elsevier.

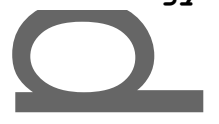

The covalent immobilisation method is not entirely efficient, and some unattached protein remains bound to the scaffold through physical interactions, and can therefore de-absorb over time. ${ }^{[24,41]}$ It is possible that this combination of soluble and immobilised growth factor act synergistically, with the soluble component diffusing from the implanted scaffold to create a concentration gradient, an important aspect of growth factor function, ${ }^{[10]}$ directing nearby cells toward the electrospun material and the immobilised drug. Although unquantified, this could potentially mitigate the lack of void filling capacity of the electrospun scaffolds since the diffused soluble component spreads through the void to interact with the surrounding tissue, potentially encouraging the tissue-material interface to migrate toward the scaffold. Covalent immobilisation strategies are limited however, as they are only relevant to drugs that can be used by cells non-destructively, where only repeated surface recognition but not internalisation is required. Furthermore, while we have shown for GDNF (discussed above) that the growth factor is active long-term, it remains to be determined if immobilisation can counteract protease-mediated degradation for other proteins. This method is also static: it cannot be used to provide a temporally varied drug delivery profile. It can be used to allow materials to present ongoing biochemical cues in addition to the physical cues, either of drugs that are required indefinitely or to increase the biomimetic quality of the scaffold material by immobilising biological components of the ECM. It is important to recognise that this is not desirable for many proteins that many only be required during a regenerative phase, having negative affects during homeostatis. For these reasons the immobilisation of growth factors to electrospun fibers is yet to be translated to clinical application. The inherent properties of electrospun materials do put some limitations on their biomimicry, and this is one of the main reasons why hydrogel materials are often more suitable.

\section{Hydrogel Materials}

Hydrogel scaffolds are of interest, as they provide an aqueous environment mimetic of the ECM, a major component of which is a cellularly secreted proteoglycan hydrogel. ${ }^{[2,42]}$ Hydrogels consist of highly hydrated interconnected chains, connected through physical or chemical crosslinking, forming a weak or strong scaffold, respectively. Physically crosslinked scaffolds can undergo shear thinning, where applied shear stress allows flow with minimal resistance (Figure 6). ${ }^{[43]}$ When the stress is removed the domains physically interconnect again to recreate the structure allowing the gel to recover its initial stiffness. ${ }^{[43]}$

This article is protected by copyright. All rights reserved. 


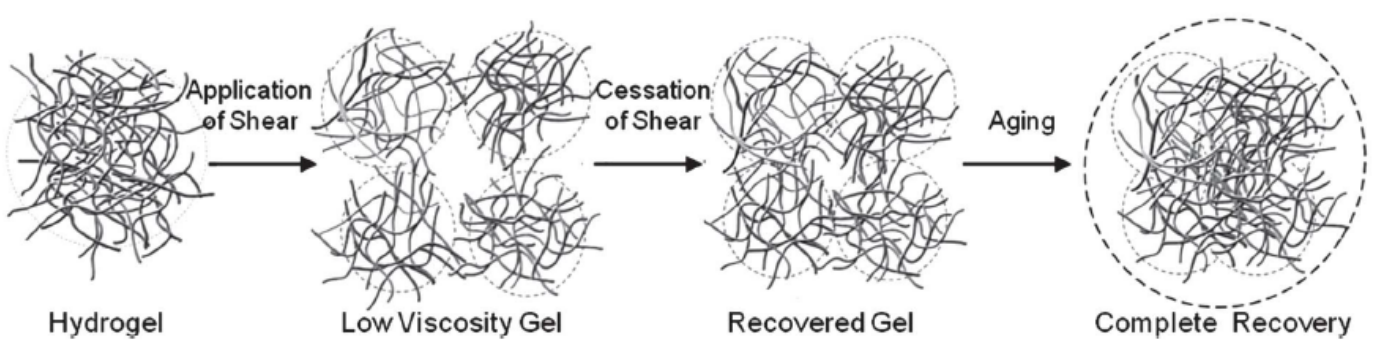

Figure 6: Hydrogel Shear Thinning and Recovery. Application of shear stress causes the hydrogel network to break into smaller domains, which flow easily around each other. When the stress is removed, the small domains reintegrate into a larger hydrogel network. Reproduced with permission. ${ }^{[43]}$ Copyright 2010, Royal Society of Chemistry.

This is a very attractive property for tissue engineering applications as the engineered material can be injected directly to the site of therapeutic need via a minimally invasive needle rather than surgically implanted. Shear-thinning also increases their void filling ability, as the thinned hydrogel flows throughout the entire injury site before the domains reassemble and the material returns to its more solid-like gel state to create a perfectly fitted implant. ${ }^{[44]}$ The true ECM is a dynamic environment, constantly changing and undergoing stress, ${ }^{[2]}$ so materials based on reversible and reformable physical interactions can potentially provide a more adaptable and appropriate scaffold.

An important class of physically formed hydrogels for biomedical applications are those that mimic the natural processes behind the formation of the ECM, exploiting the spontaneous self-assembly of bioinspired amphiphilic molecules (such as synthetic polymers, proteins, peptides, polysaccharides, and their derivatives) into higher order structures. ${ }^{[30 c, 44-45]}$ Self-assembly occurs when there is a balance between the intermolecular repulsive and solvating forces, which drive the material formation. The intermolecular interactions can include hydrophobic interactions, hydrogen bonds, $\pi-$ $\pi$ stacking of aromatic groups, and charge-charge interactions ${ }^{[44]} \mathrm{A}$ stimulus is required to initiate assembly, and must be presented as uniformly as possible to ensure homogeneity, and the rate at which the stimulus (heat, ionic strength, $\mathrm{pH}$ ) is applied must be adjusted to promote ordered structures and avoid uncontrolled aggregation or precipitation. ${ }^{[46]} \cdot{ }^{[44]}$ The catalytic action of enzymes has also been used to modify these interactions due to the formation/cleavage of bonds. For biological applications it is important that the molecular assembly occurs under physiological conditions ( $\mathrm{pH}$ 7.4, salt concentration $150 \mathrm{mM}$, temperature $37^{\circ} \mathrm{C}$ ) to ensure the desirable hydrogel structure is retained in vivo ${ }^{[47]} \mathrm{An}$ important and often overlooked property is that the final material is optically transparent, as a significant number of cell assays utilise fluorescent dyes. A number of successful approaches have been made to functionalise these materials with bioactive sequences, including charge ${ }^{[48]}$ and peptide sequence ${ }^{[49]}$ to promote cell attachment, metabolism and survival, making them exceltent candidates for the controlled biological effects of drugs. A recent development has been to develop peptide amphiphiles that incorporate a region that assembles and presents a peptide known to activate the FGF-2 receptor on supramolecular nanoribbons. This material has been shown to achieve the stable presentation of the growth factor like region in a bioavailable fashion. ${ }^{[50]}$ For more information relating the cellular response to synthetic and natural hydrogels, particularly in the central nervous system, the interested reader is directed to a number of excellent reviews on the subject. ${ }^{[25,51]}$ Hydrogels have significant potential for clinical transplation with many already being ultilized. While in this review we are focused on systemic design approaches to drug delivery, intended to inspire the readership to consider new design approaches or to engineer novel delivery systems by synergistic combination of existing strategies, we

This article is protected by copyright. All rights reserved. 
acknowledged the importances of where currently technologies are in relation to translation. Therefore, we direct the interested reader to and excellent review by the Kohane group addressing druge delivery from hydrogels, their progress and currently challenges. ${ }^{[52]}$

\subsection{Direct Addition of Drugs into Hydrogels}

The self-organising and shear thinning nature of physical hydrogels makes direct incorporation into the gel material much simpler than with electrospun materials. Soluble additives that interact with the structures can be co-assembled into the material as it forms, or can be mixed into the aqueous component of the hydrogel post assembly by simply applying minimal shear stress to thin the gel temporarily without destroying/disrupting the beneficial structures (e.g.: with a bench top vortex mixer), and then allowing the gel to reform. ${ }^{[53]}$ NGF was mixed into the self-assembling diblock copolypeptide hydrogels $\mathrm{K}_{180} \mathrm{~L}_{20}$ and $\mathrm{E}_{180} \mathrm{~L}_{20}$ and showed ongoing bioactive effect for at least 4 weeks in vivo in mice. This study demonstrated prolonged hypertrophy and a larger region of effect compared to NGF injected in a buffer solution. ${ }^{[54]}$ Although the loading is simple, the release profile of drugs and growth factors from hydrogels is dependent on interactions between the two materials. From MAX8 peptide hydrogels for example, positively charged proteins diffuse out while negatively charged proteins adsorb to the hydrogel showing little diffusion. ${ }^{[55]}$ While the electrostatic properties of different growth factors inherently result in different release profiles, so as with electrospun materials controlling the release profile again requires more involved methods. Unmodified diffusion of growth factor from hydrogels can occur very rapidly, ${ }^{[56]}$ so for growth factors in particular, for which rapid degradation means sustained delivery is required, just slowing the diffusion to provide more long-term delivery is an important goal.

\subsection{Immobilisation of Drugs in Hydrogels}

Growth factors are often immobilised, either permanently or non-permanently, via additional chemical groups with known biological affinities. Collagen hydrogels have been modified with epidermal growth factor (EGF) covalently attached to a peptide designed to bind to collagen, which was observed to improve proliferation and neuronal differentiation of neural stem cells (NSCS). ${ }^{[57]}$ Biotin tagged interferon- $\gamma$ (IFN- $\gamma$ ) and platelet derived growth factor AA (PDGF-AA) have been immobilised to a streptavidin functionalised methacryamide chitosan (MAC) hydrogel via the wellknown biotin-streptavidin conjugation. ${ }^{[58]}$ These materials showed improved neural regeneration in vivo in spinal cord injury in rats, showing increased neuron count relative to treatment with the hydrogel material alone. ${ }^{[58]}$ Similar immobilised IFN- $\gamma$ in chitosan hydrogel materials were tested with NSCs. ${ }^{[59]}$ When cultured in hydrogels functionalised with either immobilised or soluble IFN- $\gamma$, both conditions resulted in a similar improvement in neuronal differentiation compared to medium alone, but the immobilised drug showed fewer semi-committed and immature neurons, indicated by the lower co-presentation of nestin and $\beta$ III tubulin. ${ }^{[59]}$

Delayed release can be achieved by covalent immobilisation to the hydrogel material of a molecule with a weaker affinity for the drug being released. The drug is not fully immobilised to the scaffold, but held in place by a strong affinity through reversible physical bonds. This has been achieved for heparin-binding drugs by first immobilising heparin within the hydrogel. ${ }^{[60]}$ In this work, a bi-domain peptide was covalently bound to a fibrin matrix through a transglutaminase substrate on the $\mathrm{N}$ terminus, and a heparin-binding domain on the C-terminus was used to electrostatically immobilise

This article is protected by copyright. All rights reserved. 
heparin to the matrix. ${ }^{[60]}$ The heparin-binding drug, basic fibroblast growth factor (bFGF), was in turn semi-immobilised through its electrostatic interaction with heparin, and its release from the hydrogel was delayed. ${ }^{[60]}$ This approach is widely applicable to heparin binding growth factors, and has also been adapted for some non-heparin-binding factors. NGF is non-heparin binding, but its Cterminus contains several basic residues surrounded by hydrophobic residues, which is similar to a heparin-binding domain. ${ }^{[56]}$ Using a high molar excess of immobilised heparin, the release of NGF was slowed from the fibrin matrix, allowing a continuous release over 15 days compared to 1 day from fibrinalone and resulting in a $100 \%$ improvement in neurite growth compared to fibrin and NGF alone.

This heparin binding domain system is diverse, with 15 binding proteins identified so far from the platelet-derived growth factor (PDGF)/VEGF, FGF, transforming growth factor beta (TGT- $\beta$ ), and neurotrophin families. ${ }^{[61]}$ This variety shows versatility of this controlled release method for delaying the release of individual proteins, but it also highlights a significant drawback of this technique: the release profile cannot be tailored for one drug without affecting the release profile of other loaded heparin-binding drugs. Also, like many others, this method is dependent on chemical modification of the scaffold itself, which could alter some of the specifically engineered hydrogel properties, particularly (elastic) stiffness, a property that plays a major role in driving cell differentiation. ${ }^{[5]}$ This could mean that control of the dynamic environment is attained at the expense of control over the structural and mechanical environment.

The wide range of heparin-binding proteins requires additional consideration for in vivo applications where endogenous serum proteins can become involved. The use of a heparin mesh to bind bone morphogenic protein (BMP)-2 was shown to be an effective method of localising the BMP-2 delivery in vitro, however, when tested in vivo, it did not work. ${ }^{[62]}$ Competitive binding of serum proteins to the heparin in the mesh negated this effect, allowing BMP-2 to pass beyond the mesh. ${ }^{[62]}$ Heparin sulfate, which is less negatively charged and which shows less generalised affinity than heparin, has been used to mitigate this problem with BMP-2. ${ }^{[63]}$ More interestingly, this affect has also been specifically used to improve therapeutic outcomes. A customised heparin hydrogel system was designed for maximal binding of inflammatory cytokines, which inhibit wound healing, and was shown to outperform the commercial Promogran product in reducing inflammation and promoting wound healing in mice. ${ }^{[64]}$ This is an ingenious approach to combatting inflammation.

Other affinities can be used to achieve controlled growth factor presentation. For example, chemical modification of the protein of interest with $\mathrm{SH} 3$ and delivery in a material modified with an $\mathrm{SH} 3$ binding peptide. ${ }^{[65]}$ This approach has been used to successfully provide sustained Chondrotinase $A B C(C h A B C)$ delivery. ${ }^{[65]}$ As with the heparin affinity systems above, this system requires modification of the tissue engineering material, which may not always be possible or desirable. The use of ECM protein binding domains is a very interesting affinity based delivery system that does not share this drawback. In this case, rational protein engineering is used to incorporate an ECM protein binding domain into the growth factors being delivered. ${ }^{[66]}$ Martino et. al. isolated an ECM protein binding sequence isolated from PIGF-1 and fused that sequence to VEGF, PDGF, and BMP-2 with. ${ }^{\text {[66] }}$ Delivery of these protein engineered growth factors resulted in improved healing of wounds and bone defects in vivo in rodents compared to treatment with the wild type unmodified growth factors. ${ }^{[66]}$ This approach is particularly interesting because unlike most binding pair systems, it does not require modification of the tissue engineering material being used to deliver the growth factors,

This article is protected by copyright. All rights reserved. 
instead relying on the presence of ubiquitous ECM proteins (fibronectin, collagen, etc.) ${ }^{[66]}$ to immobilise the growth factors as they diffuse from the material. Many tissue engineering materials are made using ECM proteins or designed to include recognisable ECM protein epitopes. The use of this delivery system with a material already designed to include the binding partner, such as the tissue-specific self-assembling peptide (SAP) hydrogels discussed in section 3.4 below, is worth investigation. This combination could allow further control over the immobilisation and delivery of the growth factors.

\subsection{Spatial Control of Multiple Drugs in Hydrogels}

Fine 3D spatial control over drug incorporation in hydrogel materials is possible using 2-photon technology to attach molecules. ${ }^{[67]}$ In this method lasers are used to precisely determine where in the 3D hydrogel photochemical reactions occur to chemically immobilise therapeutic or binding agents. Immobilisation of a single therapeutic agent, the peptide sequence glycine-arginine-aspartic acid-serine (GRDGS) containing the RGD integrin binding sequence from fibronectin, has been used to spatiallyguide neurite outgrowth. ${ }^{[68]}$ This method has been adapted to provide independent control over multiple therapeutic agents via protein binding agents. ${ }^{[67 \mathrm{~b}]}$ Multiple protein binding agents can be immobilised first, before washing the hydrogel material with the appropriate protein solutions to allow the physical association with the binding agent to hold them in place (Figure 7). ${ }^{[67 b]}$ The nature of this procedure means that all reactive chemistry is performed before any sensitive proteins are introduced into the material. ${ }^{[67 b]}$ The method is also widely applicable to other proteins, requiring only a common biotin or barstar modification. ${ }^{[67 b]}$ The number of spatially distinct regions is limited to the number of biotin-streptavadin style binding pairs can be incorporated. Combining this technique with work being done on injectable preformed hydrogel materials with shape memory ${ }^{[69]}$ might lead to fine spatial control of drugs within an injectable hydrogel matching an irregularly shaped injury site. However, this immobilisation method does not offer advances in temporally controlled delivery over other immobilisation strategies.
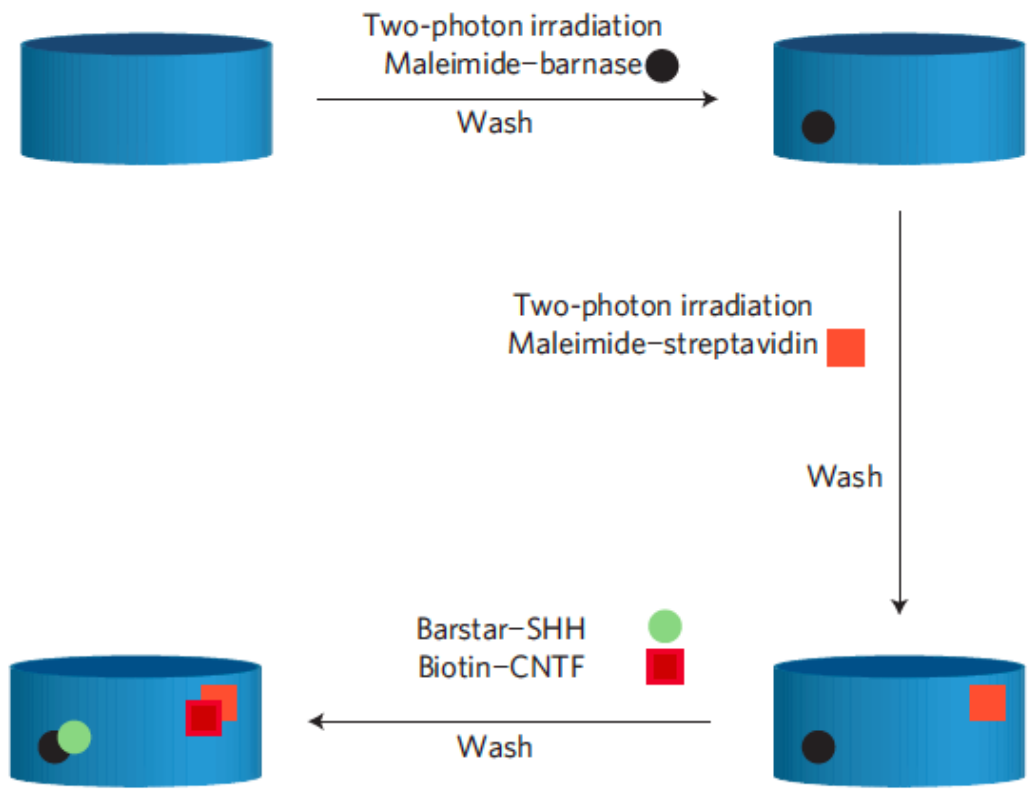

Figure 7: Method for the simultaneous immobilisation of (sonic hedgehog) SHH and CNTF. Two-photon irradiation is provided sequentially to chemically bind one half of each binding pair. The entire hydrogel is immersed in the material

This article is protected by copyright. All rights reserved. 
but fine spatial control of the two-photon irradiation limits the immobilisation reaction. Once all the first halves are bound individually, a final wash off all the binding proteins combined is used to lock them in place only where the relevant binding pair has been immobilised. Reproduced with permission. ${ }^{[67 \mathrm{~b}]}$ Copyright 2011, Nature Publishing Group.

\subsection{Responsive Hydrogels}

An immobilisation and controlled release delivery system has been achieved with enzyme sensitive linkages. Therapeutic peptide sequences flanked with matrix metalloproteinase (MMP) enzyme degradable sequences were chemically crosslinked to a PEG hydrogel structure, such that host MMP cleaved the bonds holding the therapeutic peptide in place resulting in a sustained delivery. ${ }^{[70]}$ This method has been confirmed in vivo in mice with proangiogenic SPARC sequences promoting increased vascularisation. ${ }^{[70]}$ This system is interesting as it allows drug delivery dependent on local conditions

As long as stimuli can reach the material, then in situ modulation of gel properties is possible, allowing for the engineering of stimuli-responsive hydrogel materials. Hydrogels can be engineered to respond to external stimuli such as changes in temperature, $\mathrm{pH}$, electric fields, light, and enzymes. ${ }^{[71]}$ Photodegradable hydrogels offer easy external control, such as poly(ethylene glycol)tetrathiol (PEG4SH) hydrogels, which can be degraded with only 120 seconds of low intensity UV light exposure $\left(10 \mathrm{~mW} / \mathrm{cm}^{2}, 365 \mathrm{~nm}\right) .{ }^{[71 \mathrm{~b}]}$ Here the hydrogel degradation is irreversible, meaning that once the material is degraded to release any loaded drugs it can no longer offer the same structural support. More sophisticated photo triggered release systems link the photolabile component to the bioactive component only. Poly(ethylene glycol) di-acrylate (PEGDA) hydrogels functionalised with the bioactive RGD peptide sequence have been designed with a photolabile capping blocking the RGD peptide until released by a transdermal UV trigger. ${ }^{[72]}$ This transdermal UV trigger system used lower energy $350-365 \mathrm{~nm}$ light, which was able to achieve transdermal activation without detectable harm to murine skin in vivo. ${ }^{[72]}$ However, penetration depth is still a concern ${ }^{[72]}$ and, as is common with photo stimulated systems, is not suited for deep tissue applications.

Perhaps the most promising stimuli-responsive mechanisms for targeted drug delivery are the antigen responsive hydrogels. These can be tailored to respond to stimuli found at the site of therapeutic need, for example, hydrogels that swell in the presence of a specific disease associated antigen can be created by modifying the polymer chains with paired antibodies and antigens (Figure 8). ${ }^{[73]}$ In the absence of free antigen, the bound antibodies and antigens interact, creating more crosslinking points in the gel and essentially keeping the matrix very tight. When free antigen is present, some of the antibody-antigen interactions within the hydrogel are disrupted in favour of interactions with the free antigen, which lowers the degree of crosslinking and essentially loosens the gel. This process is reversible ${ }^{[73]}$ and since the degree of crosslinking in a hydrogel is directly linked to its permeability ${ }^{[74]}$ this system can provide pulsatile release of active agents responding to changing free concentrations of the antigen. ${ }^{[73]}$

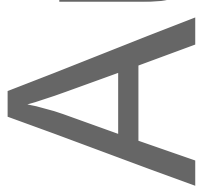

This article is protected by copyright. All rights reserved. 

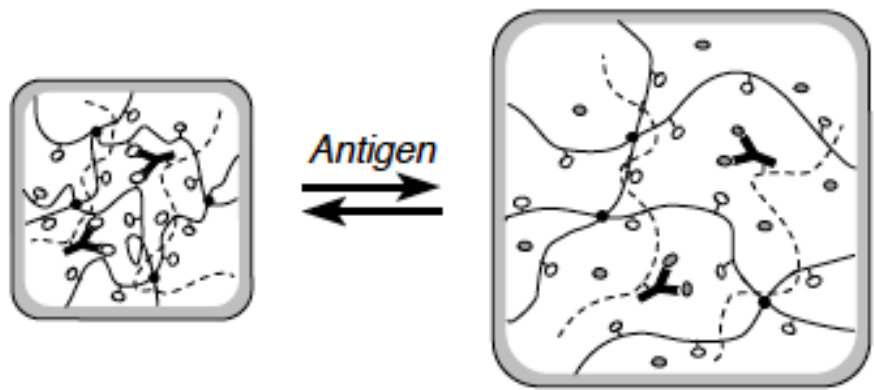

\section{Antibody-immobilized polymer chain Antigen-immobilized polymer chain}

: Free antigen

Figure 8: Antigen Responsive Hydrogel. Antibodies and corresponding antigens are bound to the hydrogel chains, and increase the interconnectivity of the hydrogel network when they pair. Free antigen in the surrounding environment reduces the number of bound antibody-antigen pairs and decreases the interconnectivity of the hydrogel. Reproduced with permission. ${ }^{[73]}$ Copyright 1999, Nature Publishing Group.

Interestingly, this approach can be used to respond to externally controlled signals, or to automatically react to naturally arising cues. When foreign antigens, such as fluorescein isothiocyanate $(\mathrm{FTCC})^{[75]}$ or rabbit lgG, ${ }^{[73]}$ are used as trigger molecules, the release profile can be controlled independently of any ongoing biological processes. These materials are not naturally occurring in the body, so drug release can only be triggered by the controlled introduction (such as via injection) of the foreign antigen. The highly specific nature of antibody interactions means that even very similar antigens will not trigger release ${ }^{[73]}$ so complete and independent control of the release profite is retained. Alternatively, hydrogels can be designed to respond to predefined natural cues and automatically release the appropriate therapeutic agent. This approach also offers a potential way around the issues involved with the large size of protein growth factors, such as bypassing the blood brain barrier. A molecule that can cross the BBB can be selected as the trigger, such that systemic delivery can be used to trigger release of growth factors if not to deliver them.

Glucose responsive hydrogels have been engineered to act as an artificial pancreas to provide automatic pulsatile release of insulin as needed. ${ }^{[76]}$ Several systems have been explored for glucose responsive insulin delivery. Lectin proteins that bind to carbohydrates have been used in a similar system to the antigen-antibody interactions described above. ${ }^{[7]}$ Other systems incorporate reactive agents into the hydrogel mesh that affect charge changes in the presence of glucose and swell the gel via increased electrostatic repulsion between polymer chains. ${ }^{[76]}$ Glucose oxidase immobilised onto the polymer chains converts glucose to gluconic acid, which can in turn protonate tertiary amines on appropriate hydrogelating polymers, such as dimethylaminoethyl methacrylate (DMA), thereby swelling the hydrogel via electrostatic repulsion between chains. ${ }^{[76]} A$ non-enzymatic system based on phenylboronic acid (PBA) complexes with glucose and other 1,2 or 1,3-cis-diols to form an anionic group. ${ }^{[71 a, 77]}$ The PBA approach is less specific, but offers improved longevity over systems dependant on proteins that degrade over time. ${ }^{[77]}$

Responsive swelling gels are only applicable for the release of entrapped large molecules, such as proteins, whose transport depends on the hydrogel mesh size and permeability. ${ }^{[75]}$ However, during

This article is protected by copyright. All rights reserved. 
swelling, the hydrogel properties can change significantly; this may change the mechanical properties, alter support provided to the surrounding tissue, modify the void fraction of the material, and significantly alter the pharmacokinetic release profile of entrapped drugs. ${ }^{[52]}$ The approach can be adapted for smaller drugs by covalently attaching the small drug molecule to larger gelling molecules by a cleavable linker. ${ }^{[78]}$ This also adds a second stage to the mediation of the drug release, as linkers can be selected that are susceptible to proteases expressed by disease cells to increase targeting efficiency. ${ }^{[78]} \mathrm{A}$ common theme among stimuli-responsive hydrogels is the alteration of gel properties to facilitate release. Even if temporary, this is still undesirable in tissue engineering materials where the hydrogel properties have been optimised to provide optimal structural and mechanical cues to the surrounding cells. Ideal tissue engineering materials must be designed to concurrently provide an ongoing structurally supportive environment and controlled drug delivery.

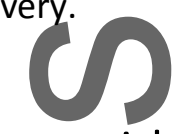

\section{Nanoparticles in Tissue Engineering Materials}

Drug encapsulation in nanoparticles is a simple shielding procedure that allows for diverse functionalisation. Polymer materials with excellent biocompatibility and biodegradability can be used to create the nanoparticles, which can then be made to incorporate fluorescent or radioactive tags for diagnostic imaging, targeting moieties for location specific delivery, and delayed or stimuliresponsive release mechanisms. ${ }^{[79]}$ Once encapsulated, drugs can be incorporated directly into hydrogels ${ }^{[80]}$ or electrospinning solutions. ${ }^{[81]}$ Encapsulation also provides shielding to protect the drug from interactions with solvents used in electrospinning and harsh chemicals such as acids and bases used to induce gelation, making nanoparticles attractive for delivery of sensitive or reactive drugs.

Using this approach, epidermal growth factor (EGF) and erythropoietin (EPO) have been presented sequentially to stimulate endogenous NSPCs to heal after stroke. ${ }^{[80]} \mathrm{EGF}$ encapsulated in polylacticco-glycolic acid (PLGA) nanoparticles and EPO encapsulated in PLGA and further coated in polysebacic acid (PSA) were incorporated in a hyaluronan methylcellulose (HAMC) hydrogel to provide sequential delayed release. ${ }^{[80]}$ EGF release was observed from days 4-11, while EPO release was observed from days $11-25 .{ }^{[80]}$ When tested in vivo with mice, this functionalised nanoparticle and hydrogel system showed similar results in terms of cell differentiation and proliferation when compared to a standard mechanical pump system used to control drug delivery from implanted reservoirs, demonstrating state of the art drug delivery control from a minimally invasive and biodegradable material. ${ }^{[80]}$ Similarly, nanoparticle loaded growth factors can also be loaded into electrospun materials to provide sequential delivery, with the nanoparticle loaded growth factor being delayed. Wound dressings have been prepared by electrospinning a chitosan/PEO blend loaded with free VEGF, which showed a burst release, and PLGA nanoparticles loaded with PDGF-BB, which showed a sustained ongoing release. ${ }^{[82]}$

There is a vast array of stimuli responsive nanoparticle drug delivery vehicles ${ }^{[83]}$ and often these can be incorporated into tissue engineering materials to essentially achieve the same stimuli-responsive control of drug delivery discussed above without disrupting material properties. Silica nanoparticles have been modified with photo-sensitive attachment of small molecules drugs and then mixed into a PEG hydrogel to demonstrate photo-triggered drug release from a hydrogel. ${ }^{[84]}$ Nanoparticle systems

This article is protected by copyright. All rights reserved. 
also offer stimuli responsive behaviour not available otherwise, such as magnetically controlled delivery. Superparamagnetic $\mathrm{Fe}_{3} \mathrm{O}_{4}$ nanoparticles have been incorporated into a poly $(\mathrm{N}-$ isopropylacrylamide) (PNIPAAm) hydrogel, which is reverse temperature responsive, to provide remote triggered drug delivery ${ }^{[85]}$ and pulsatile on-off delivery ${ }^{[86]}$ upon application of an alternating magnetic field. However, in this system the drug was loaded into the hydrogel, and once again the control of delivery depended on altering the material properties of the hydrogel, in this case by using the magnetically responsive nanoparticles to increase the temperature in the thermally responsive hydrogel, ${ }^{[85-86]}$ making it useful as a controllable drug reservoir but not as a general method for drug delivery from tissue engineering materials.

For tissue engineering applications particularly, where structural support is also a concern, electrospun nanofibre fragments and nanocarriers for drugs are a promising strategy. Electrospun scaffolds can be fragmented via ultrasonication ${ }^{[87]}$ or microtome cutting ${ }^{[1 b]}$ into short nanofibres that retain the morphological benefits of electrospun materials and can be dispersed into hydrogels to form composite biomaterials. Natural collagen and poly-(3-caprolactone-co-D,L-lactide) (P(CL:DLLA) have been fragmented via ultrasonication and dispersed within hyaluronan methylcellulose (HAMC) hydrogels without losing the desirable mechanical properties of the hydrogel. ${ }^{[88]}$ We have prepared nanofibre fragments via cutting with a microtome and have used the fragment nanofibres as growth factor delivery vehicles by cutting from an electrospun scaffold that had GDNF immobilised to it. ${ }^{[89]}$ These growth factor modified nanofibre fragments were dispersed in a xyloglucan hydrogel, and were able to improve cell survival of ventral midbrain (VM) dopamine progenitor cell grafts in Parkinsonian mice, while also increasing the reinnervation of the striatum. ${ }^{[1 \mathrm{~b}]}$ The potential for electrospun nanofibre fragments as growth factor and other drug delivery vehicles is vast, as all of the previously discussed methods of drug incorporation can be used to control drug delivery, while the fragmentation and combination with hydrogels adds flexibility.

\section{Conclusion}

Many techniques used to provide drug delivery systems from tissue engineering materials use the material as a biodegradable depot, which is definitely preferably to invasive micropumps, ${ }^{\left[{ }^{[00}\right]}$ but is not achieving the full potential of drug delivery tissue engineering materials. Both the constant supportive environment-the physical, chemical, and biological cues mimicking a healthy ECM-and dynamic temporally controlled drug/growth factor delivery are important considerations in tissue engineering and they affect each other. Truly optimised tissue engineering systems needs to consider both of these topics in their design, and need to be able to control them independently. Additionally, distinet delivery profiles of multiple drugs or growth factors from a single material requires independent control, and controlling the degradation of the tissue engineering material can only provide a single delivery profile. Immobilisation using ECM protein affinities is an excellent example of an incorporated growth factor delivery system designed in such a way as to avoid altering the tissue engineer material. This independent control makes the delivery system well suited for use with many different materials. However, the dynamic control offered by an immobilisation strategy is limited.

While growth factor stabilisation and immobilisation are important aspects of drug delivery, they do not provide the full range of therapeutic delivery profiles. This field progresses with research into

This article is protected by copyright. All rights reserved. 
individual aspects of tissue engineering material properties and drug delivery systems, and with so many options explored individually the potential for combination and potential synergy in future research is very exciting, and hopefully combinations of methods explored here can provide more options for temporally distinct/sequential delivery. Further advances in fine control of temporal delivery profiles will likely come from combinations of materials and systems discussed here to achieve increasingly more complex systems.

\section{Acknowledgements}

K. F. Bruggeman was supported by a Natural Sciences and Engineering Research Council of Canada (NSERC) Postgraduate Scholarship Doctoral (PGS D) award. R. J. Williams was supported via an Alfred Deakin ResearchFellowship. NHMRC Dementia Research Leadership Fellowship (GNT1135657).

\section{References}

[1] a) A. L. Rodriguez, T. Y. Wang, K. F. Bruggeman, C. C. Horgan, R. Li, R. J. Williams, C. L. Parish, D. R. Nisbet, J. Mater. Chem. B 2014, 2, 7771; b) T. Y. Wang, K. F. Bruggeman, J. A. Kauhausen, A. L. Rodriguez, D. R. Nisbet, C. L. Parish, Biomaterials 2016, 74, 89; c) A. L. Rodriguez, D. R. Nisbet, C. L. Parish, in Stem Cells and Cancer Stem Cells, Volume 4, Springer Netherlands 2012, p. 97.

[2] C. Frantz, K. M. Stewart, V. M. Weaver, Journal of Cell Science 2010, 4195.

[3] F. M. Watt, W. T. S. Huck, Nature Reviews Molecular Cell Biology 2013, 14, 467.

[4] M.P. Lutlof, H. J. A, Nature Biotechnology 2005, 23, 47.

[5] a) A. J. Engler, S. Sen, H. L. Sweeney, D. E. Discher, Cell 2006, 677; b) N. D. Leipzig, M. S. Shoichet, Biomaterials 2009, 30, 6867.

[6] H. V. Unadkat, M. Hulsman, K. Cornelissen, B. J. Papenburg, R. K. Truckenmuller, G. F. Post, M. Uetz, M. J. T. Reinders, D. Stamatialis, C. A. van Blitterswijk, J. de Boer, PNAS 2012, 109, 16565.

[7] a) D. E. Jaalouk, J. Lammerding, Nature Reviews Molecular Cell Biology 2009, 10, 63; b) J.-Y. Jang, S. W. Lee, S. H. Park, J. W. Shin, C. W. Mun, S.-H. Kim, D. H. Kim, J.-W. Shin, Journal of Biomedicine and Biotechnology 2011.

[8] A. E. Rodda, L. Meagher, D. R. Nisbet, J. S. Forsythe, Progress in Polymer Science 2014, 39, 1312.

[9] Q. Li, W. H. Cheung, K. L. Chow, R. G. Ellis-Behnke, Y. Chau, Nanomedicine 2012, 8, 748.

[10] P. Tayalia, D. J. Mooney, Adv Mater 2009, 21, 3269.

[11] T.-Y. Wang, K. A. F. Bruggeman, R. K. Sheean, B. J. Turner, D. R. Nisbet, C. L. Parish, J. Biol. Chem. 2014, 289, 15044.

[12] K. Lee, E. A. Silva, D. J. Mooney, J R Soc Interface 2011, 8, 153.

[13] Y. Wang, M. J. Cooke, N. Sachewsky, C. M. Morshead, M. S. Shoichet, J Control Release 2013, $172,1$.

[14] V. Gudi, J.Skuljec, O. Yildiz, K. Frichert, T. Skripuletz, D. Moharregh-Khiabani, E. Voss, K. Wtissel, S. Wolter, M. Stangel, PLoS One 2011, 6, e22623.

[15] A. C. Richards Grayson, I. S. Choi, B. M. Tyler, P. P. Wang, H. Brem, M. J. Cima, R. Langer, nature materials 2003, 2, 767.

[16] S. W. Kemp, A. A. Webb, S. Dhaliwal, S. Syed, S. K. Walsh, R. Midha, Exp Neurol 2011, 229, 460.

[17] a) C. E. Krewson, W. M. Saltzmann, Brain Research 1996, 727, 169; b) R. W. Sirianni, P. Olausson, A. S. Chiu, J. R. Taylor, Saltzman, W M, Brain Research 2010.

This article is protected by copyright. All rights reserved. 
[18] E. R. Edelman, M. A. Nugent, M. J. Karnovsky, Proc. Natl. Acad. Sci. 1993, 90, 1513.

[19] C. E. Krewson, W. M. Saltzman, Brain Research 1996, 727, 169.

[20] M. Sudhakar, R. Kancharla, V. U. Rao, Pharmanest 2013, 4, 142.

[21] K. F. Bruggeman, A. L. Rodriguez, C. L. Parish, R. J. Williams, D. R. Nisbet, Nanotechnology 2016, 27, 385102.

[22] J. Stockwell, N. Abdi, X. Lu, O. Maheshwari, C. Taghibiglou, Chem Biol Drug Des 2014, 507.

[23] X. Li, Y. Qian, I. Liu, X. Hu, G. Zhang, Y. You, S. Liu, Biomaterials 2011, 32, 6595.

[24] M. K. Horne, D. R. Nisbet, J. S. Forsythe, C. L. Parish, Stem Cells Dev 2010, 19, 843.

[25] D. R. Nisbet, J. S. Forsythe, W. Shen, D. I. Finkelstein, M. K. Horne, Journal of Biomaterials Applications 2009, 24, 7.

[26] X. Wang, B. Ding, B. Li, Materials Today 2013, 16, 229.

[27] a) D. R. Nisbet, A. E. Rodda, D. I. Finkelstein, M. K. Horne, J. S. Forsythe, W. Shen, Colloid Surface B 2009, 71, Cp1; b) M. Zamani, M. P. Prabhakaran, S. Ramakrishna, Int J Nanomed 2013, 8, 2997; c) T. J. Sill, H. A. von Recum, Biomaterials 2008, 29, 1989.

[28] N. G. Rim, C. S. Sin, H. Hin, Biomedical Materials 2013, 1.

[29] S. N. Jayasinghe, Analyst 2013, 128, 2215.

[30] a) T. Y. Wang, J. S. Forsythe, C. L. Parish, D. R. Nisbet, Journal of Biomaterials Applications 2012, 27, 369; b) E. S. Place, J. H. George, C. K. Williams, Chemical Society Reviews 2008, 38, 1139 ; c) S. A. Sell, P. S. Wolfe, K. Garg, J. M. McCool, I. A. Rodriguez, G. L. Bowlin, Polymers 2010, 2, 522 .

[31] Y.-S. Lee, T. Livingston Arinzeh, Polymers 2011, 3, 413.

[32] M. Kisiel, M. M. Martino, M. Ventura, J. A. Hubbell, J. Hilborn, D. Ossipov, Biomaterials 2013, J. M. Chen,

[33] J. M. Chen, J. K. Xu, A. L. Wang, M. H. Zheng, Expert Rev Med Devic 2009, 6, 61.

[34] a) W. Huang, T. Zou, S. Li, J. Jing, X. Xia, X. Liu, PharmaSciTech 2013, 14, 675; b) X. L. Xu, L. X. Yang, X. Y. Xu, X. Wang, X. S. Chen, Q. Z. Liang, J. Zeng, X. B. Jing, J Control Release 2005, 108, 33; C) H. X. Qi, P. Hu, J. Xu, A. J. Wang, Biomacromolecules 2006, 7, 2327.

[35] P. Zahedi, Z. Karami, I. Rezaeian, S.-H. Jafari, P. Mahdaviani, A. H. Abdolghaffari, M. Abdollahi, Journal of Applied Polymer Science 2012, 124, 4174.

[36] J. Hu, L. Tian, M. Prabhakaran, X. Ding, S. Ramakrishna, Polymers 2016, 8, 54.

[37] S. Y. Chew, J. Wen, E. K. F. Yim, K. W. Leong, Biomacromolecules 2005, 6, 2017.

[38] C. R.Wittmer, T. Claudepierre, M. Reber, P. Wiedemann, J. A. Garlick, D. Kaplan, C. Egles, Adv Funct Mater 2011, 21, 4202.

[39] a) M. Maleki, M. Latifi, M. Amani-Tehran, S. Mathur, Polymer Engineering and Science 2013;

b) A. K. Moghe, B. S. Gupta, Polym Rev 2008, 48, 353.

[40] D. Han, A. J. Steckl, ACS Applied Materials and Interfaces 2013, 5, 8241.

[41] T. Y. Wang, J. S. Forsythe, D. R. Nisbet, C. L. Parish, Biomaterials 2012, 33, 9188.

[42] a) J. L. Drury, D. J. Mooney, Biomaterials 2003, 24, 4337; b) A. S. Gobin, J. L. West, Faseb J 2002, 16, 751 .

[43] C.Yan, A.Altunbas, T. Yucel, R. P. Nagarkar, J. P. Schneider, D. J. Pochan, Soft Matter 2010, 6, 5143

[44] M. Guvendiren, H. D. Lu, J. A. Burdick, Soft Matter 2012, 8, 260.

[45] a) M. M. Giraud Guille, C. Helary, S. Vigier, N. Nassif, Soft Matter 2010, 6, 4963; b) W. Zhao, X. Jin, Y. Cong, L. Yuying, J. Fu, Journal of Chemical Technology and Biotechnology 2013, 88, 327; C) M. N. Collins, C. Birkinshaw, Carbohydrate Polymers 2013, 92, 1263.

[46] R. Li, C. C. Horgan, B. Long, A. L. Rodriguez, L. Mather, C. J. Barrow, D. R. Nisbet, R. J. Williams, RSC Adv. 2015, 5, 301.

[47] R. J. Williams, T. E. Hall, V. Glattauer, J. White, P. J. Pasic, A. B. Sorensen, L. Waddington, K. M. McLean, P. D. Currie, P. G. Hartley, Biomaterials 2011, 32, 5304. 
[48] E. V. Alakpa, V. Jayawarna, A. Lampel, K. V. Burgess, C. C. West, S. C. J. Bakker, S. Roy, N. Javid, S. Fleming, D. A. Lamprou, J. L. Yang, A. Miller, A. J. Urquhart, P. W. J. M. Frederix, N. T. Hunt, B. Peault, R. V. Ulijn, M. J. Dalby, Chem 2016, 1, 512.

[49] C. Tondera, R. Wieduwild, E. Roder, C. Werner, Y. X. Zhang, J. Pietzsch, Adv Funct Mater 2017, 27.

[50] C. M. Rubert Pérez, Z. Álvarez, F. Chen, T. Aytun, S. I. Stupp, ACS Biomaterials Science \& Engineering 2017, DOI: 10.1021/acsbiomaterials.7b00347.

[51] a) C. J. C. Edwards-Gayle, I. W. Hamley, Org Biomol Chem 2017, 15, 5867; b) N. Singh, M. Kumar, J. F. Miravet, R. V. Ulijn, B. Escuder, Chemistry 2017, 23, 981.

[52] T. R. Hoare, D. S. Kohane, Polymer 2008, 49, 1993.

[53] N. Javid, S. Roy, M. Zelzer, Z. Yang, J. Sefcik, R. V. Ulijn, Biomacromolecules 2013, 14, 4368.

[54] B. Song, J. Song, S. Zhang, M. A. Anderson, Y. Ao, C. Y. Yang, T. J. Deming, M. V. Sofroniew, Biomaterials 2012, 33, 9105.

[55] M. C. Branco, D. J. Pochan, N. J. Wagner, J. P. Schneider, Biomaterials 2010, 31, 9527.

[56] S. E. Sakiyama-Elbert, J. A. Hubbell, J Control Release 2000, 69, 149.

[57] E. Y. Egawa, K. Kato, M. Hiraoka, T. Nakaji-Hirabayashi, H. Iwata, Biomaterials 2011, 4737.

[58] H. Li, T. R. Ham, N. Neill, M. Farrag, A. E. Mohrman, A. M. Koenig, N. D. Leipzig, Adv Healthc Mater 2016, 5, 802.

[59] N. D. Leipzig, R. G. Wylie, H. Kim, M. S. Shoichet, Biomaterials 2011, 57.

[60] S. E. Sakiyama-Elbert, J. A. Hubbell, J Control Release 2000, 65, 389.

[61] M. M. Martino, P. S. Briquez, A. Ranga, M. Lutlolf, J. A. Hubbell, PNAS 2013, 110, 4563.

[62] M.H. Hettiaratchi, C. Chou, N. Servies, J. M. Smeekens, A. Cheng, C. Esancy, R. Wu, T. C. McDevitt, R. E. Guldberg, L. Krishnan, Tissue Eng Part A 2017, 23, 683.

[63] D. S. Bramono, S. Murali, B. Rai, L. Ling, W. T. Poh, Z. X. Lim, G. S. Stein, V. Nurcombe, A. J. van Wijnen, S. M. Cool, Bone 2012, 50, 954.

[64] N. S. Lohmann, Lucas; Atallah, Passant; Wandel, Elke; Ferrer, Ruben A; Werner, Carsten; Simon, Jan C; Franz, Sandra; Freudenber, Uwe;, Sci. Transl. Med. 2017, 9.

[65] M. M. Pakulska, K. Vulic, M. S. Shoichet, J Control Release 2013, 171, 11.

[66] M. M. B. Martino, Priscilla S.; Güç, Esra; Tortelli, Federico; Kilarski, Witold W; Metzger, Stephanie; Rice, Jeffrey J.; Kuhn, Gisela A.; Müller, Ralph; Swartz, Melody A.; Hubbell, Jeffrey A.; Science 2014, 343, 885.

[67] a) J. C. Hoffman, J. L. West, Soft Matter 2010, 5056; b) R. G. Wylie, S. Ahsan, Y. Aizawa, K. L. Maxwell, C. M. Morshead, M. S. Stoichet, nature materials 2011, 10, 799.

[68] Y. Luo, M. S. Shoichet, Nat Mater 2004, 3, 249.

[69] S. A.S. Bencherifa, R Warren; Bhatta, Deen; Aranya, Praveen; Verbeke, Catia S; Edwardsa, David A;, D. J. Mooney, PNAS 2012, 109, 19590.

[70] A. H.Van Hove, K. Burke, E. Antonienko, E. Brown, 3rd, D. S. Benoit, J Control Release 2015, 217, 191.

[71] a) R. Yoshida, T. Okano, in Biomedical Applications of Hydrogels Handbook, Springer Science + Business Media 2010, p. 19; b) B. Fairbanks, S. P. Singh, C. N. Bowman, K. S. Anseth, Macromolecules 2011, 44, 2444.

[72] T. T. Lee, J. R. Garcia, J. I. Paez, A. Singh, E. A. Phelps, S. Weis, Z. Shafiq, A. Shekaran, A. Del Campo, A. J. Garcia, Nat Mater 2015, 14, 352.

[73] T. Miyata, N. Asami, T. Uragami, Nature 1999, 399, 766.

[74] C. Cha, J. H. Jeong, J. Shim, H. Kong, Acta Biomaterialia 2011, 7, 3719.

[75] R. Zhang, A. Bowyer, R. Eisenthal, J. Hubble, Biotechnology and Bioengineering 2007, 97, 976.

[76] A. Guiseppi-Elie, S. I. Brahim, D. Narinesingh, Advanced Materials 2002, 14, 743.

[77] A. Matsumoto, T. Ishii, J. Nishida, H. Matsumoto, K. Kataoka, Y. Miyahara, Angew Chem 2012, 2166.

This article is protected by copyright. All rights reserved. 
[78] K. J. C. van Bommel, M. C. A. Stuart, B. L. Feringa, J. van Esch, Org. Biomol. Chem. 2005, 2917.

[79] Y. Xiao, H. Hong, A. Javadi, J. W. Engle, W. Xu, Y. Yang, Y. Zhang, T. E. Barnhart, W. Cai, S. Gong, Biomaterials 2012, 33, 3071.

[80] Y. Wang, M. J. Cooke, N. Sachewsky, C. M. Morshead, M. S. Shoichet, Journal of Controlled Release 2013, 172, 1.

[81] M. Beck-Broichsitter, M. Thieme, J. Nguyen, T. Schmehl, T. Gessler, W. Seeger, S. Agarwal, A. Grenier, T. Kissel, Macromol Biosci 2010, 10, 1527.

[82] Z. Xie, C. B. Paras, H. Weng, P. Punnakitikashem, L. C. Su, K. Vu, L. Tang, J. Yang, K. T. Nguyen, Acto Biomater 2013, 9, 9351.

[83] S. Mura, J. Nicolas, P. Couvreur, Nat Mater 2013, 12, 991.

[84] S. Shah, P. K. Sasmal, K. B. Lee, J Mater Chem B Mater Biol Med 2014, 2, 7685.

[85] N. S. Satarkar, J. Zach Hilt, Acta Biomater 2008, 4, 11.

[86] N. S.Satarkar, J. Z. Hilt, J Control Release 2008, 130, 246.

[87] M. Sawawi, T. Y. Wang, D. R. Nisbet, G. P. Simon, Polymer 2013, 54, 4237.

[88] A. Hsieh, W. Zahir, Y. Lapitsky, B. Amsden, W. Wan, M. S. Shoichet, Soft Matter 2010, 6, 2227.

[89] R. Li, S. Pavuluri, K. Bruggeman, B. M. Long, A. J. Parnell, A. Martel, S. R. Parnell, F. M.

Pfeffer, A. J. Dennison, K. R. Nicholas, C. J. Barrow, D. R. Nisbet, R. J. Williams, Nanomedicine 2016, 12, 1397.

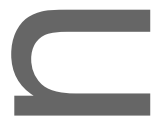

Kiara Bruggeman completed her PhD in Engineering at The Australian National University in 2017, after Honours Bachelor's degrees in Nanotechnology Engineering (2012) and in Chemistry (2013) at The University of Waterloo, Canada. Her research focuses on the development of nano-biomaterials for tissue engineering and regenerative medicine.

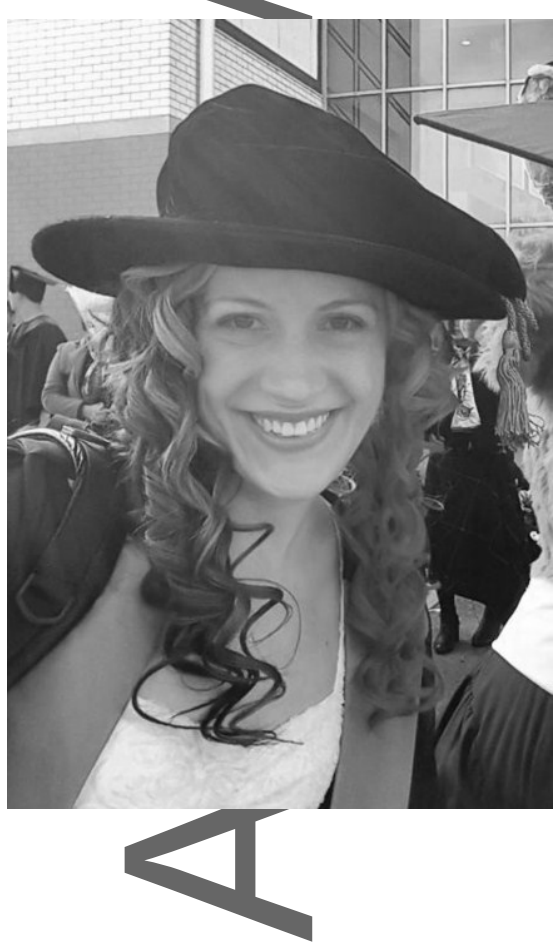

Richard Williams is Senior Lecturer in Biomaterials and Tissue Engineering at RMIT University, Melbourne. He was awarded his PhD from the University of Manchester in 2009, and was an Alfred Deakin Research Fellow at Deakin University. His expertise is in design, control and fabrication of self-assembling systems for biomedical applications.

This article is protected by copyright. All rights reserved. 


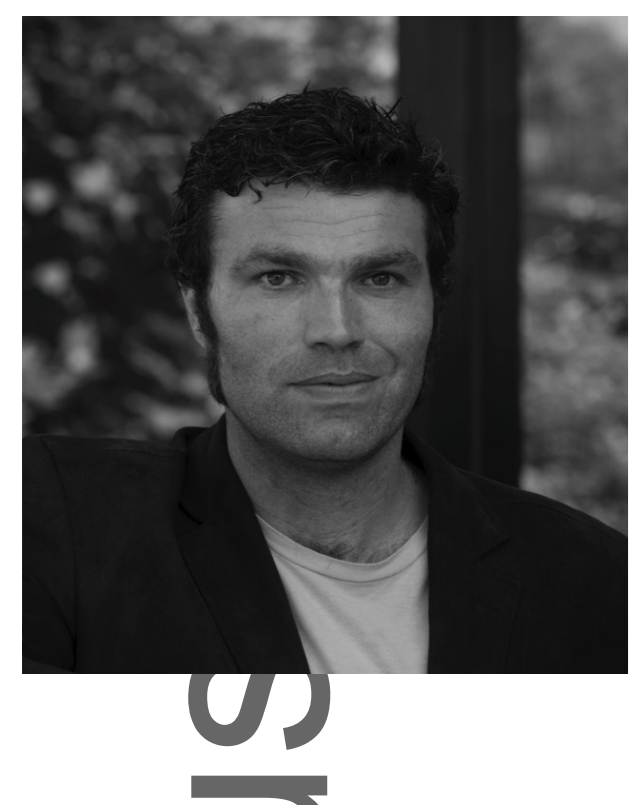

David Nisbet is an Associate Professor in the Research School of Engineering at the Australian National University and the Head of the Laboratory of Advanced Biomaterials. Dave joined the ANU after completing his PhD at Monash University and postdoctoral Fulbright scholarship at the University of California, Berkeley. He is currently a recipient of a NHMRC Dementia Research Leadership Fellowship. He is passionate about developing novel biomaterials, with focus on their translation towards clinical applications.

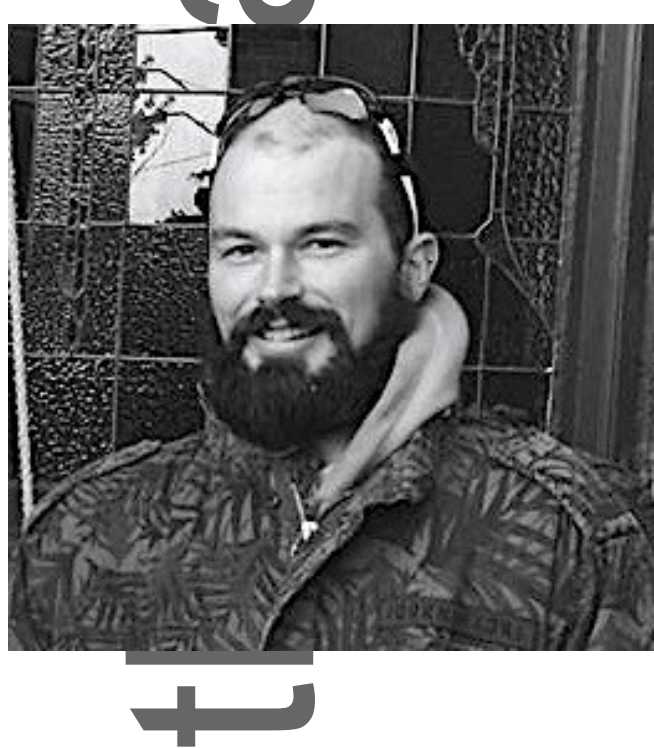

Tissue engineering materials need to be able to provide ongoing structural support as well as dynamically controlled drug delivery for optimal therapeutic outcomes. Electrospun and hydrogel materials are popular tissue engineering scaffolds for providing structural support, and this Progress Report explores the pros and cons of different drug delivery systems being developed for use in these materials.

\section{Tissue Engineering}

K. F. Bruggeman ${ }^{1}$, R. J. Williams ${ }^{2,3 *}$, D. R. Nisbet ${ }^{1,3}$ *

This article is protected by copyright. All rights reserved. 
Dynamic and Responsive Growth Factor Delivery from Electrospun and Hydrogel Tissue Engineering Materials
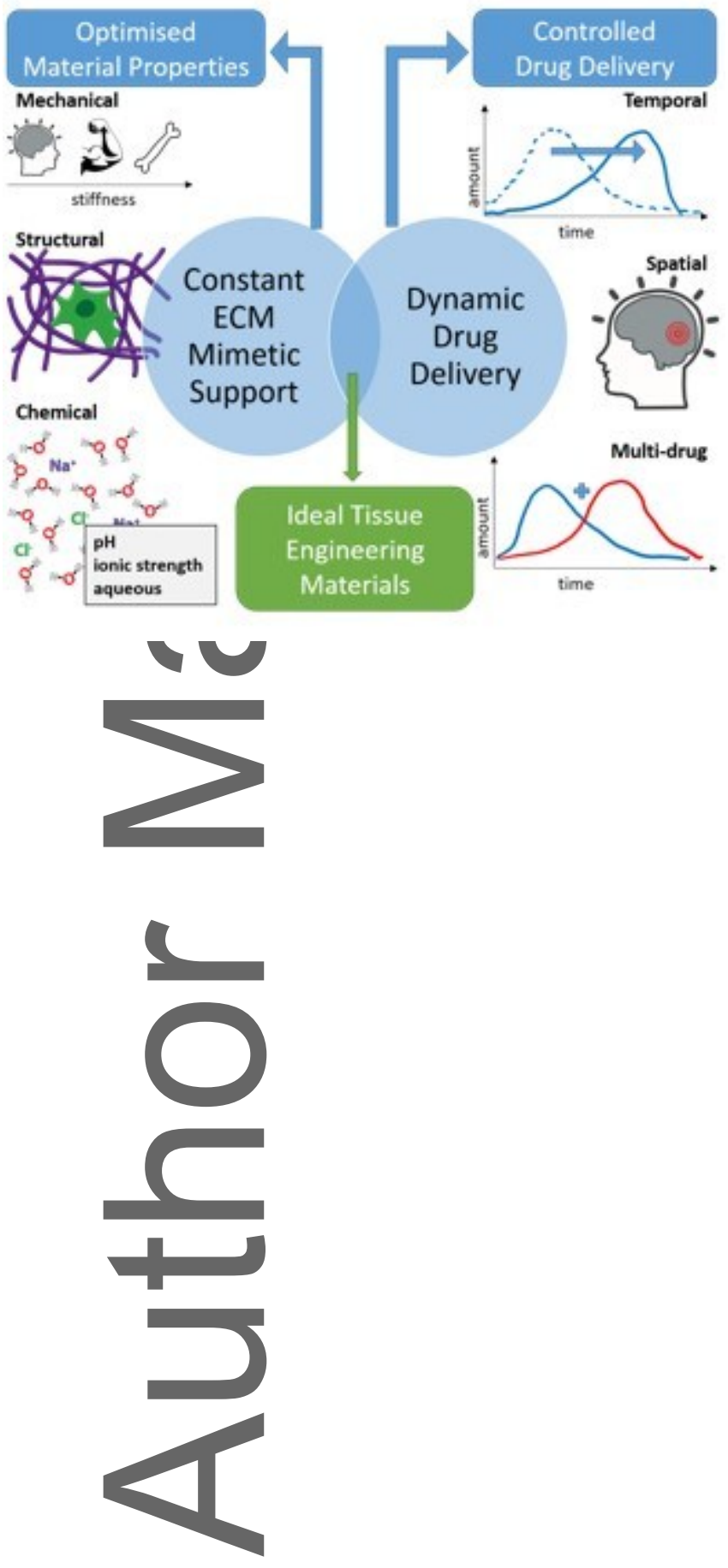

This article is protected by copyright. All rights reserved. 


\section{University Library}

\section{- M M N E R VA A gateway to Melbourne's research publications}

Minerva Access is the Institutional Repository of The University of Melbourne

Author/s:

Bruggeman, KF;Williams, RJ;Nisbet, DR

Title:

Dynamic and Responsive Growth Factor Delivery from Electrospun and Hydrogel Tissue Engineering Materials

Date:

2018-01-10

Citation:

Bruggeman, K. F., Williams, R. J. \& Nisbet, D. R. (2018). Dynamic and Responsive Growth Factor Delivery from Electrospun and Hydrogel Tissue Engineering Materials. ADVANCED HEALTHCARE MATERIALS, 7 (1), https://doi.org/10.1002/adhm.201700836.

Persistent Link:

http://hdl.handle.net/11343/293945 